\title{
UTAUT'S performance consistency: Empirical evidence from a library management system
}

\author{
A.M. Zainab ${ }^{1,2}$, K. Kiran ${ }^{1}$, N.H.A Karim ${ }^{1}$ and M.Sukmawati ${ }^{2}$ \\ ${ }^{1}$ Department of Library and Information Science, \\ Faculty of Computer Science and Information Technology, \\ University of Malaya, Kuala Lumpur, MALAYSIA \\ ${ }^{2}$ Perpustakaan Hamzah Sendut, University of Science Malaysia, \\ Gelugor, Penang, MALAYSIA \\ e-mail: zainabajab@siswa.um.edu.my; kiran@um.edu.my (corresponding author); \\ nharun@um.edu.my; sukmawati@usm.my
}

\begin{abstract}
This paper aims to investigate the use of an adapted UTAUT model to explore librarians' acceptance of Radio-frequency Identification based Library Management System (RFID-LMS) and to determine the performance consistency of UTAUT when applied in a context other than its original intent. Causal relationships between the five identified constructs and their significances are determined using multiple regression method. The results are then compared to the performance of UTAUT as reported in the originating article. The relationship between external variables, attitude and selfefficacy, along with UTAUT constructs and RFID-LMS acceptance were found to be significant. The reliability of the modified UTAUT was found to be consistent with the original UTAUT. These findings have implications on the theoretical foundations of UTAUT and supports the notion of a unified view of examining technology adoption and diffusion.
\end{abstract}

Keywords: UTAUT; RFID; Library Management System (LMS); Adoption; Information systems.

\section{INTRODUCTION}

The rapid growth in technology has increased the demands and expectations of library services. In the modern library, the services are managed by a Library Management System (LMS), usually an integrated system which incorporates various modules based on library functions, such as acquisitions, cataloguing, circulation, serials management, etc. In current systems, the overlying technology for the LMS is the Radio-Frequency Identification (RFID). The RFID based LMS (RFID-LMS) is built on various technology platforms to increase efficiency and effectiveness of repetitive and time-consuming library tasks (Dwivedi et al. 2013). There are organizational, technological and individual factors that influence librarians' acceptance and use of technology. Despite the fact that patron self-checking and patron satisfaction have been recognized as the two most imperative benefits of RFID application in libraries (Dwivedi et al. 2013), literature reveal a slow uptake of RFID-LMS. Research focusses either on the technology (Bingsi and Xiaojing 2006) or the satisfaction of library patrons (Andaleeb and Simmons, 1998; Dwivedi et al. 2013). There has barely been any effort to empirically investigate librarians' acceptance of this technology. Hence, this empirical study investigates the influencing factors on librarians' acceptance of RFID based LMS. 
Technology acceptance and use has its roots in theories used to examine adoption and diffusion, specifically in the evolving models of Theory of Reasoned Action (TRA), technology acceptance model (TAM), theory of planned behaviour (TPB), innovation diffusion theory (IDT), among others. When Venkatesh et al. (2003) in their effort to integrated constructs from various adoption and diffusion models, introduced the Unified Theory of Acceptance and Use of Technology (UTAUT), they intended for it to be a comprehensive model adaptable to any type of technology. The model has been widely used since its inception, but very few studies make the effort to relate their findings to support the robustness of the original model.

This study therefore is twofold. Building on previous work, the objectives of this study are:

a) to examine the acceptance of RFID-LMS by librarians using a modified UTAUT model with two additional determinants, attitude and self-efficacy

b) ascertain the performance of UTAUT with regards to its reliability and consistency across different contexts as compared to its original intent.

The paper is organized as follows: the next section will provide a critical review of the related literature to highlight the need of an examination of librarians' acceptance of RFIDLMS. This is followed by a description of the method utilized to collect and analyse the data. In subsequent sections, the paper presents its argument on the performance consistency of UTAUT and makes recommendations based on the conclusions of this study.

\section{LITERATURE REVIEW}

In the field of Information System and Information Technology, the aim, prediction and explanation of individual behaviour towards the acceptance of new technologies are very decisive. An in-depth study on the individual's behaviours toward the acceptance and use of new technologies by means of technology acceptance models and theories are quiet common. The acceptance model broadcast the aim, prediction and explanation of individual behaviours. It has been acknowledged by various studies (Venkatesh et al. 2003; Schaper and Pervan 2007; Wu, Tao and Yang 2007) that the UTAUT model contributes to better understanding about the determinants of behaviour of acceptance and use of new technologies compared to other similar theories and models.

\section{Unified Theory of Acceptance and Use of Technology (UTAUT)}

The UTAUT model has four direct determinants, namely performance expectancy (PE), effort expectancy (EE), social influence (SI) and facilitating condition (FC) to measure both behavioural intention and actual behaviour (Venkatesh et al. 2003). These four main constructs are used in the environmental focused study (Tibenderana and Ogao 2009) and environment intentions. In studies on acceptance and use, the UTAUT model constructs are modified to ensure the adaptability of the constructs to suit the user performance in using technology based application. Since its inception, the UTAUT has been extensively adapted and adopted in investigating the general acceptance and usage of ICT in different environment or cultures (Anderson and Schwager 2004; Louho, Kallioja and Oittinen 2006; Kripanont 2007; Schaper and Pervan 2007; Al-Qeisi 2009; Tibenderana and Ogao 2009; Zhou, Lu and Wang 2010; Ain, Kaur and Waheed 2015).

A meta-analysis by Dwivedi et al. (2011) identified several external variables used by other studies in adapted versions of UTAUT, among which are attitude, anxiety, self-efficacy, trust, perceived ease-of use, perceived usefulness, etc. that have significant, not significant or mixed influence on behavioural intentions. Behavioural intention is seen as a critical 
predictor of technology use. In general, they report that the reliability of the UTAUT instrument was consistent in all studies that have used it. This justified the continual use of UTAUT for various types of technologies in different fields.

\section{Use of UTAUT in Library Services Research}

In library services, UTAUT has been used quiet extensively, either in its original form or adapted accordingly to suit the intentions of the study. The four main construct are normally retained by researchers and their relationships with intentions and use explored repeatedly. These relationships are also confirmed by Santos-Feliscuzo and Himang (2011), Chang (2013), Chang et al. (2015), and Vongjaturapat et al. (2015) in the context of library services.

Santos-Feliscuzo and Himang (2011) investigated the acceptability of the Library Periodical Indexing Software in terms of its performance expectancy, effort expectancy, social influence and facilitating condition. They found the effects of moderating variables, gender, age, experience and voluntariness of use to be significant. Besides UTAUT construct, technical qualities of the software were also assessed for further improvement of the system. Chang (2013) integrated UTAUT with task-technology fit moderator to explain users' behavioural intention of using library mobile applications. She found the model to fit the data well. Another study by Chang et al. (2015) attempted to integrate UTAUT and website service quality, compiling it into a usage behavioural model for university library electronic resources. Their findings in Taiwan public and private universities revealed that $\mathrm{PE}, \mathrm{SI}$ and website service quality are antecedents to behavioural intention and FC positively affect use behaviour.

Vongjaturapat et al. (2015) used UTAUT and the Task-technology fit (TFF) model to study the acceptance of tablet use in library information services in Thailand. They found significant effect of TFF on both PE and actual use of tablet among university students. In Indonesia, Wasitarini and Tritawirasta (2015) report on the use of UTAUT to investigate the acceptance of closed access library service system through OPAC and Integrated Library Information System INLIS applications at the Indonesian National Library. The variables measured included PE, EE, SI and FC. However, the authors do not report the effects of these constructs as indicators of behavioural intentions. So no data is available to examine the performance consistency of UTAUT in relation to library technology. An interesting alternative use of Venkatesh et al.'s UTAUT is by Pervaiz and Brogan (2016) who explored e-book user behaviour based on the constructs. Though the model was not explicitly tested, E-book users' information behaviour was found to be consistent with major technology adoption theories and frameworks. Facilitating conditions was the only construct found to be not significant in the original UTAUT (Venkatesh et al. 2003). They later positioned it as direct influence on use rather than acceptance behaviour.

\section{RFID based LMS}

The RFID based LMS is the main system used for the entire library services and processes. It has its own developed technology which may vary from one library to another. For years' libraries have been using the barcode system, which is labour intensive and offers less security. More recently a large number of libraries have changed to RFID LMS system, but the uptake is slow and challenging. The reason for this slow uptake and optimum use of the RFID technology in libraries is not evident. One of the solutions is to understand librarians' acceptance of the system in use. 
Undertaking this study defines how the RFID based LMS helps librarians in terms of performance expectancy (PE) in their daily task at the library. It is assumed that the librarians believe that using the RFID based LMS system will help the librarians to improve their job performance. The librarians' effort expectancy (EE) and knowledge to use the system with and without experience is gathered. This is to see the level of ease associated with the use of RFID based LMS among the librarians. The librarians' attitude toward using technology (ATUT) to replace a manual system is observed. The librarians' attitude and needs for a RFID based LMS system is examined. The social influence (SI) to use and acceptance the RFID based LMS technology in the library and the ability of the librarians to use the RFID based LMS to accomplish the daily tasks is observed via librarian's selfefficacy (SE). The outcome of the librarians' acceptance of RFID based LMS is the measure of the degree to which a librarian has formulated a conscious plan to implement or not to undertake the acceptance of the technology.

It should be noted that the UTAUT model has rarely been applied in RFID-LMS related studies, especially in a developing country like Malaysia. This research is a pioneer in technology acceptance using the UTAUT model focussing on a library management system.

\section{THE CONCEPTUAL FRAMEWORK}

The use of any pre-existing model calls for several adaptations to the context of the study. A model is adopted if the intentions is to test the reliability and data fit of the model in a new context or it can be adapted to suit the new context with modified variables. These variables of course should be used with strong and logical justifications (Dwivedi et al. 2011).

In this approach, the current study considers the original Unified Theory of Acceptance and Use of Technology, UTAUT, and its variant available in research literature to develop the conceptual framework to investigate the acceptance of RFID-LMS. UTAUT is deemed appropriate as it is a product of the assimilation and evolution of eight theories on technology acceptance and use. The framework is as shown in Figure 1. The framework consists of five independent variables extracted from the original UTAUT (performance expectancy, effort expectancy, social influence) and from related literature (attitude towards technology and self-efficacy).

The facilitating condition construct is removed and replaced with two users' reflective behaviour constructs which are the attitude towards using technology (ATUT) and selfefficacy (SE). The attitude towards using technology (ATUT) and self-efficacy (SE) are adopted from UTAUT model focused to an open source technology adoption (Gallego, Luna and Bueno 2008). In the 2003 model, the effect of these determinants are moderated by gender, age, experience and voluntariness of use. The moderating effect in the UTAUT model is not a mandatory field unless the usage of a testing system is confirmed to be adopted (Venkatesh et al. 2003). Therefore, in this study the moderating constructs are removed and the focus is on the four main determinants; performance expectancy (PE), effort expectancy (EE), attitude towards using technology (ATUT), social influence (SI) and self-efficacy (SE) of the UTAUT model.

The modified UTAUT model has five independent variables to measure the acceptance of RFID-LMS technology in an academic library. These independent variables are hypothesized to influence the librarians' acceptance of using an RFID-LMS. 


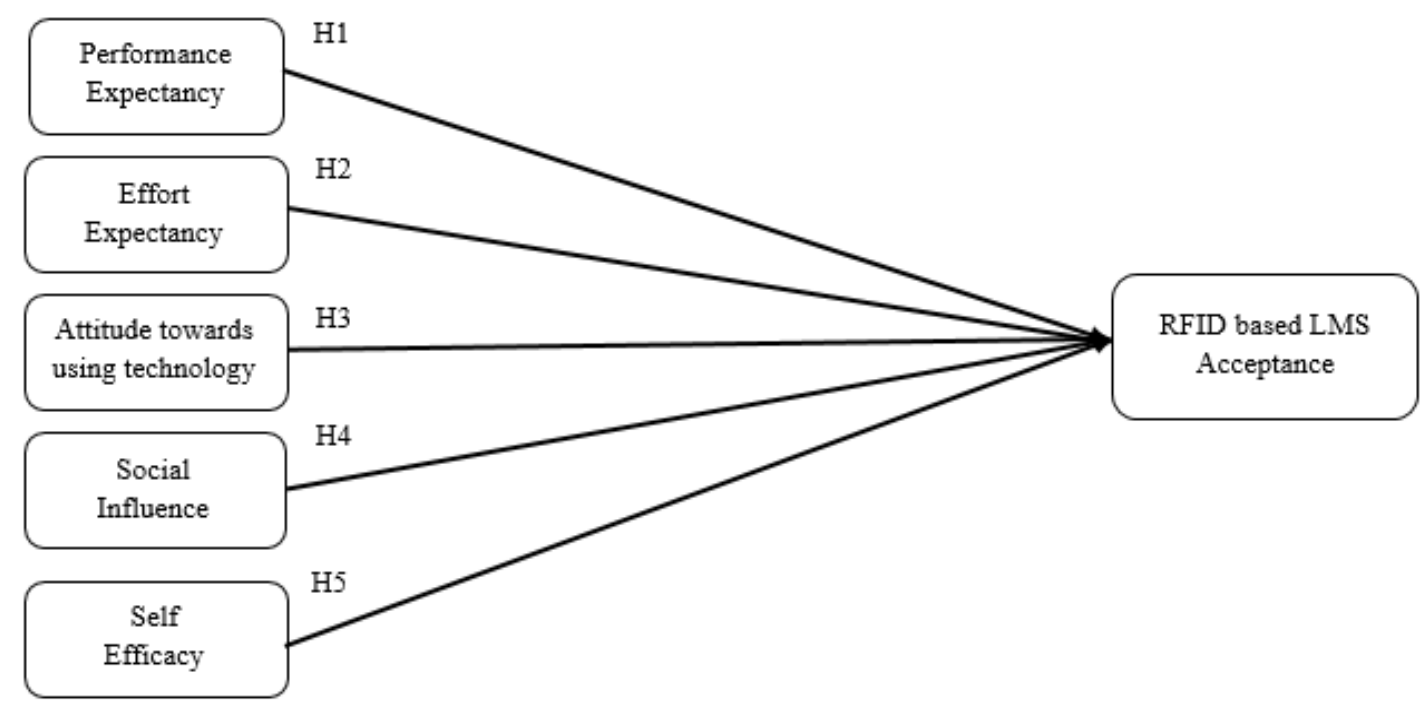

Figure 1: The Conceptual Framework

\section{i. Performance Expectancy (PE)}

According to Venkatesh et al. (2003), performance expectancy is the degree to which individuals' belief using a technology to perform different activities will provide benefits to the user. Waheed et al. (2015) and Ain et al. (2015) reported a significant direct effect of PE on behavioural intention to use a technology. It is assumed that librarian belief that RFID-LMS will be useful in their tasks leads to the justification of examining PE as a determinant in this study.

Thus, the first hypothesis is:

H1. Performance expectancy has a positive influence on the acceptance of RFID-LMS

\section{ii. Effort Expectancy (EE)}

The second construct is the degree of ease associated with consumers' use of technology (Venkatesh et al. 2003). The effort expectancy is the element of behavioural intention to use a technology and effort expectancy is from the perspective of an organization settings, employee assess time and effort in forming views about the overall effort associated with consumers' acceptance and technology used (Venkatesh et al. 2003). Though Ain et al. (2015) found that students reported EE to not have an effect on their acceptance of learning management systems, Chang (2013) found EE to be significant in students use of library mobile applications. In this study it is expected that when librarian feel it is easy to use RFID-LMS and it does not require much effort from them, they will be more willing to accept and use the RFID-LMS. Therefore, it is hypothesized:

H2. Effort expectancy has positive influence on the acceptance of RFID-LMS

\section{iii. Attitude Towards using of Technology (ATUT)}

The third construct is the behavioural intention to determine the technology used. The chosen technology used is determining the attitude of the consumers towards accepting the technology. Attitude is 'the perceived degree of positive and negative feelings about 
the target behaviour' (Ajzen 1991). In this study it is the positive feelings about using RFIDLMS. This leads to the following hypotheses:

H3. Attitude towards using technology has positive influence on the acceptance of RFIDbased LMS

\section{iv. Social Influence (SI)}

Social factors are specific cultural and interpersonal influences on an individual from the significant others that the individual believes can influence his/her use of a new technology. Venkatesh et al. (2003) defined it as the degree to which an individual perceives that important others believe he should use the new system'. Chang (2013) found SI to be significant among students' acceptance of mobile library services, but Carlsson et al. (2006) found it to be not significant. This study examines if Librarian are influenced by others when deciding on accepting and using the RFID based LMS system. The following hypothesis examines this relationship:

H4. Social influence using technology has positive influence on the acceptance of RFID based LMS

\section{v. Self-Efficacy (SE)}

Self-efficacy is an individual's perception about their own ability or skill to perform a task (Bandura 1986). The users' self-efficacy plays a vital role in building attitudes towards technology and its adoption (Waheed et al. 2015). The UTAUT model of this study also explains how the librarians as individuals have difference influence on technology. The relationship of the construct and criterion indicates the users' acceptance of the RFID-LMS in the library. The UTAUT model will be able to enhance the librarians understanding for the technology acceptance.

H5. Self-efficacy using technology has positive influence on the acceptance of RFID based LMS

Thus, the UTAUT model is used as an extended model to study the librarians' acceptance and use of RFID-LMS technology in university libraries.

\section{METHOD}

An appropriate method in empirical studies involving testing of models is the survey method, employing a questionnaire. This section details the instrument used, the sampling procedure and the administration of the survey instrument.

\section{Survey Instrument}

The data gathering instrument was a self-administered questionnaire. The questionnaire included demographic questions and acceptability items based on the conceptual framework explained in Figure 1. Most item were adopted from Venkatesh et al. (2003) and related studies from Gallego, Luna and Bueno (2008), Jasimudeen (2013) and Zhussupova and Rahman (2011) with some modifications to suit the context of a university library management system. The items were subjected to face validity and content validity by a panel of experts in RFID and LMS. The panel of experts examined and verified the permission letter to conduct the study, the instructions provided to the respondents, the length of the questionnaire and total number of questions. Each item in the questionnaire 
was checked for grammar, sentence structure, and ambiguity. The expert panel further commented that each item appropriately measured the construct as defined by the researcher. All items were found to be acceptable by the panel of experts, thus no changes were required to the format nor the content of the questions. A total of 21 items were designed to measure the constructs on a five-point Likert scale. The scale used was $1=$ strongly disagree; 2 =disagree; $3=$ neither agree nor disagree; $4=$ agree and $5=$ strongly agree. Each statement is presented according to the constructs grouping of the independent variables. Items mapping each construct are as shown in Table 4.

\section{Data Collection}

Data was collected from librarians in a particular university library using random sampling. By using the GPower software (3.1.9.2) with 6 predictors and effect size of 0.2 and confident level is set to $90 \%, 95 \%$ and $99 \%$ the appropriate sample size for the study is 56 . The questionnaires were distributed to 100 librarians with an expected response rate of 60 percent. However, the return rate was higher than expected. A total of 90 librarians returned the questionnaire and all responses were subjected to further analysis. Roscoe's rule of thumb for appropriate sample selection for a behavioral study mentions that a sample less than 10 is not recommended, for experimental research 30 samples are recommended and a sample of about 10 percent of the population is recommended (Roscoe, 1975). Therefore, this study has an adequate sample size.

\section{RESULTS}

In this section, the results of the validity and reliability of the instrument are presented. Followed by output of the factor analysis and finally the multiple regression to test the research hypotheses.

\section{Demographic Data}

Demographic details of the respondents in terms of gender, age and experience are shown in Table 1. The table depicts that the largest proportion of the respondents are males (52\%), and those between the ages of $31-40$ years (46.7\%). There is an almost equal distribution of librarians' experience, with 35.6 percent having experience more than 14 years; 34.4 percent between $5-14$ years; and 30 percent less than 5 years.

Table 1: Demographic Profile of Respondents

\begin{tabular}{llcc}
\hline \hline & Characteristic & Frequency & Percentage \\
\hline \hline Gender & Male & 47 & 52.0 \\
& Female & 43 & 47.8 \\
\hline \hline \multirow{3}{*}{ Age } & $21-30$ years & 12 & 13.3 \\
& $31-40$ years & 42 & 46.7 \\
\hline \hline \multirow{3}{*}{ Experience } & $>40$ years & 36 & 40.0 \\
& < 5 years & 27 & 30.0 \\
& $>14$ years & 31 & 34.4 \\
\hline \hline
\end{tabular}




\section{Reliability and Validity}

The instrument is checked for reliability based on Cronbach's alpha value. Table 2 shows the value of Cronbach's alpha for all six construct, all between $0.799-0.872$, indicating high reliability or internal consistency. This implies all items for each individual construct are highly internally consistent. The items are above the threshold of 0.7 and indicate the reliability of the instrument. The number of items used for the study is 21 and none of the items were discarded during the reliability and validity of the instrument. Therefore, the items are well adapted and accepted for this study.

Table 2: Reliability Test

\begin{tabular}{lcc}
\hline \multicolumn{1}{c}{ Constructs } & Cronbach's Alpha, $\alpha$ & No of items \\
\hline \hline Performance Expectancy & 0.799 & 3 \\
\hline \hline Effort Expectancy & 0.723 & 3 \\
\hline \hline Attitude towards using technology & 0.805 & 4 \\
\hline \hline Social Influence & 0.830 & 4 \\
\hline \hline Self-Efficacy & 0.830 & 4 \\
\hline \hline RFID based LMS & 0.872 & 3 \\
\hline \hline
\end{tabular}

\section{Factor Analysis}

The factor analysis is determined by using the Kaiser-Meyer-Olkin measure (KMO) of sampling adequacy with Bartlett's Test of Sphericity. When $p \leq .05$ and the value of the KMO measure of sampling adequacy is set to 0.6 and 1.0 as in Table 3 . This study shows that the KMO is above 0.6 and well accepted. The variance explained is high and subsequently, alleviates the common method bias (CMB). Therefore, Harmon Single Factor Score is used to measure and is loaded into one common factor. Therefore, the total variance obtained for a single factor is $48 \%$ and is less than $50 \%$. Hence, common method bias does not affect the data and results obtained.

Table 3: KMO and Bartlett Test

\begin{tabular}{lccc}
\hline \multicolumn{1}{c}{ Construct } & $\begin{array}{c}\text { KMO } \\
0.6<\mathrm{KMO}<1.0\end{array}$ & $\begin{array}{c}\text { Bartlett's test } \\
\text { sig }\end{array}$ & Variance explained \\
\hline \hline Performance Expectancy & 0.652 & 0.00 & 71.987 \\
\hline \hline Effort Expectancy & 0.635 & 0.00 & 65.192 \\
\hline \hline Attitude towards using technology & 0.701 & 0.00 & 66.473 \\
\hline \hline Social influence & 0.795 & 0.00 & 66.779 \\
\hline \hline Self-Efficacy & 0.784 & 0.00 & 67.177 \\
\hline \hline RFID based LMS & 0.709 & 0.00 & 80.076 \\
\hline \hline
\end{tabular}

Factor loading indicates the effect on the constructs. The loading can range from -1 to +1 . The loading which is 0 indicates the weak effect on the constructs. Table 4 shows the factor loading of the constructs and the items. The result of factor loadings for performance expectancy (PE), effort expectancy (EE), attitude towards using technology (ATUT), social influence (SI), self-efficacy (SE) and RFID based LMS (RFID-LMS) are above the threshold value 0.7. Hence, the factor loadings are accepted and indicate strong effect on the constructs. The factor loading obtained for this study which is above the threshold 0.7 indicates the high reliability of this study constructs for the instrument. 
The descriptive statistics of the six constructs which are analysed in this study is as shown in Table 5. The mean and standard deviation is used to summarise the continuous data. The standard deviation also indicates how much the constructs of a group differ from the mean value for the particular group. In this study, the standard deviation indicates the data are closer to the mean.

Table 4: Factor Loadings

\begin{tabular}{lc}
\hline \hline \multicolumn{1}{c}{ Constructs } & Factor Loading \\
\hline Performance Expectancy [PE] & 0.782 \\
\hline I find RFID based LMS useful in my job & 0.907 \\
\hline Using RFID based LMS enables me to accomplish tasks quickly & 0.851 \\
\hline Using RFID based LMS increases task productivity & 0.719 \\
\hline Effort Expectancy [EE] & 0.869 \\
\hline Interaction with RFID based LMS is clear and understandable & 0.827 \\
\hline It is easy to become skilful at using RFID based LMS & \\
\hline I find RFID based LMS easy to use & 0.858 \\
\hline Attitude towards using technology [ATUT] & 0.888 \\
\hline Using RFID based LMS is a good idea & 0.851 \\
\hline RFID based LMS makes my daily job more interesting & 0.812 \\
\hline Hands-on with RFID based LMS is fun & 0.684 \\
\hline I like working with RFID based LMS & 0.879 \\
\hline Social Influence [SI] & 0.858 \\
\hline $\begin{array}{l}\text { IT personnel from the automation division influence the library management to } \\
\text { deploy RFID based LMS }\end{array}$ & 0.833 \\
\hline Library management think that librarians should use RFID based LMS & \\
\hline Librarians have been helpful in the use of RFID based LMS & 0.875 \\
\hline In general, the library has supported the use of RFID based LMS & 0.808 \\
\hline Self-Efficacy [SE] & 0.928 \\
\hline I can complete a task using RFID based LMS even if there is no one around to tell \\
me what to do
\end{tabular}

Table 5: Descriptive Statistics of the Constructs

\begin{tabular}{llc}
\hline \hline \multicolumn{1}{c}{ Constructs } & Mean & Standard Deviation \\
\hline \hline Performance Expectancy & 3.607 & 0.72 \\
\hline \hline Effort Expectancy & 3.656 & 0.62 \\
\hline \hline Attitude towards using technology & 3.694 & 0.62 \\
\hline \hline Social Influence & 3.620 & 0.60 \\
\hline \hline Self-efficacy & 3.431 & 0.63 \\
\hline \hline RFID based LMS & 3.626 & 0.68 \\
\hline \hline
\end{tabular}


The Pearson correlation coefficient $(r)$ is used to measure the strength between the variables. The Pearson's $r$ range from -1 to +1 . The $r \leq-1$ shows the perfect negative linear relationship between constructs, $r=0$ shows there is no linear relationship between constructs and $r \geq+1$ indicates a perfect linear relationship between constructs. The correlation coefficient between constructs is shown in Table 6 . The result shows a perfect positive correlation among the constructs.

Table 6: Correlation between Constructs

\begin{tabular}{lcccccc}
\hline \hline Pearson Correlation & RFID-LMS & PE & EE & ATUT & SI & SE \\
\hline RFID-LMS & 1.00 & - & - & - & - & - \\
\hline PE & $.626^{* *}$ & 1.00 & - & - & - & - \\
\hline EE & $.479^{*}$ & $.401^{*}$ & 1.00 & - & - & - \\
\hline ATUT & $.634^{* *}$ & $.413^{*}$ & $.738^{* *}$ & 1.00 & - & - \\
\hline SI & $.573^{*}$ & $.393^{*}$ & $.640^{* *}$ & $.559^{*}$ & 1.00 & - \\
\hline SE & $.634^{* *}$ & $.287^{*}$ & $.578^{*}$ & $.594^{*}$ & $.778^{* *}$ & 1.00 \\
\hline $\begin{array}{l}\text { Correlation is significant at } 0.01 \text { level }(1 \text { tailed) } \\
* *\end{array}$ \\
$*$ Strong positive influence \\
Moderate positive influence
\end{tabular}

There exists stronger linear relationship and this is indicated by the correlation coefficient between -1 and 1 . The value in table 6 are all positive, therefore a positive relationship exists and the variables move in the same direction. The strength of the Pearson's correlation coefficient is recognized in the performance expectancy (PE), attitude towards using technology (ATUT) and self-efficacy (SE). These are strong predictors whereas effort expectancy (EE) and social influence (SI) moderately predicts the relationship.

There is strong positive relationship between effort expectancy and attitude towards using technology $(r=.738, p<.001)$; social influence and self-efficacy $(r=.778, p<.001)$ and effort expectancy and social Influence $(r=.640, p<.001)$. There is moderate positive relationship between performance expectancy and effort expectancy $(r=.401, \mathrm{p}<.001)$; performance expectancy and attitude towards using technology $(r=.413, p<.001)$; performance expectancy and social influence $(r=.393, p<.001)$; performance expectancy and selfefficacy $(r=.287, p<.001)$; effort expectancy and self-efficacy $(r=.578, p<.001)$; attitude and social influence $(r=.559, \mathrm{p}<.001)$; and attitude and self-efficacy $(r=.594, p<.001)$.

A strong positive influence between performance expectancy and RFID based LMS ( $r=.626$, $\mathrm{p}<.001)$; attitude and RFID based LMS ( $r=.634, \mathrm{p}<.001)$; and self-efficacy and RFID based LMS $(r=.634, p<.001)$ is also evident. The outcome positively moderates the influence for the effort expectancy and RFID based LMS $(r=.479, \mathrm{p}<.001)$ and social influence and RFID based LMS $(r=.573, p<.001)$.

\section{Multiple Regression}

The regression analysis is used to test the research model. Table 7 shows regression analysis for the research model. The confident level was set to $95 \%$ and $90 \%$ with $p<.005$ and $p<.010$. The variance in RFID based LMS acceptance with the model statistically significance at sig $=.000 ; p<.005$. Thus, the performance expectancy (Beta=.210; sig=.000; $p>.005$ ) and attitude towards using technology (Beta=.593; sig $=.000 ; p>.005$ ) positively influence the RFID based LMS acceptance. The other construct that positively influence the RFID based LMS acceptance is the effort expectancy (Beta=.247; sig=.003; $p<.005$ ) and 
self-efficacy (Beta $=.654 ;$ sig $=.001 ; p<.005)$. The social influence predictor moderately influencing the RFID based LMS acceptance (Beta $=.653 ; \mathrm{sig}=.007 ; \mathrm{p}<.010$ ).

Table 7: Research Model Regression Analysis

\begin{tabular}{lcccc}
\hline \multirow{2}{*}{ Constructs } & \multicolumn{2}{c}{ Collinearity Statistics } & Standardized Coefficient & Sig. \\
\cline { 2 - 5 } & Tolerance & VIF & Beta & ${ }^{*} \mathrm{p}<0.005, * * 0.010$ \\
\hline \hline PE & 0.791 & 1.264 & .210 & $0.000^{*}$ \\
\hline \hline EE & 0.375 & 2.664 & .247 & $0.003^{*}$ \\
\hline \hline ATUT & 0.380 & 2.631 & .593 & $0.000^{*}$ \\
\hline \hline SI & 0.265 & 3.774 & .653 & $0.007^{* *}$ \\
\hline \hline SE & 0.349 & 2.862 & .654 & $0.001^{*}$ \\
\hline \hline
\end{tabular}

The goodness of fit of this study model is determined by the $R^{2}$ value. In this study the $R^{2}$ value is .578 and it shows that $58 \%$ perfectly fit the data. Therefore, the model is accepted for the RFID based LMS acceptance. Table 8 shows the hypotheses constructed with the findings and Figure 2 illustrated the hypotheses with final model with affecting factors which influences on the acceptance of RFD based LMS in university libraries. The rejected hypothesis is shown as dashed line in Figure 2.

Table 8: Hypotheses Testing

\begin{tabular}{lc}
\hline \hline \multicolumn{1}{c}{ CONSTRUCTS } & HYPOTHESES \\
\hline \hline H1. Performance expectancy has a positive influence on the acceptance of & Supported \\
RFID based LMS & \\
\hline \hline H2. Effort expectancy has positive influence on the acceptance of RFID based & Supported \\
LMS & \\
\hline \hline H3. Attitude towards using technology has positive influence on the & Supported \\
acceptance of RFID based LMS & \\
\hline \hline H4. Social influence using technology has positive influence on the acceptance \\
of RFID based LMS
\end{tabular}

\section{DISCUSSIONS}

This section discusses the findings based on the main objectives of this study. The acceptance of RFID-LMS by librarians using a modified UTAUT model with two additional determinants, attitude and self-efficacy is discussed based on the results of the proposed model testing. The original UTAUT model, with direct determinants of performance expectancy (PE), effort expectancy (EE), social influence ( $\mathrm{SI}$ ) and facilitating condition (FC), measures the actual behavior of technology acceptance in the environmental focused study. In this study, the facilitating condition is replaced with attitude towards using technology (ATUT) and self-efficacy (SE). The purpose was to highlight the users' reflective behavior on acceptance to use the RFID based LMS technology. Both the proposed constructs are shown to have strong positive influence on the acceptance of RFID based LMS by the users in this behavioral aspects study. 


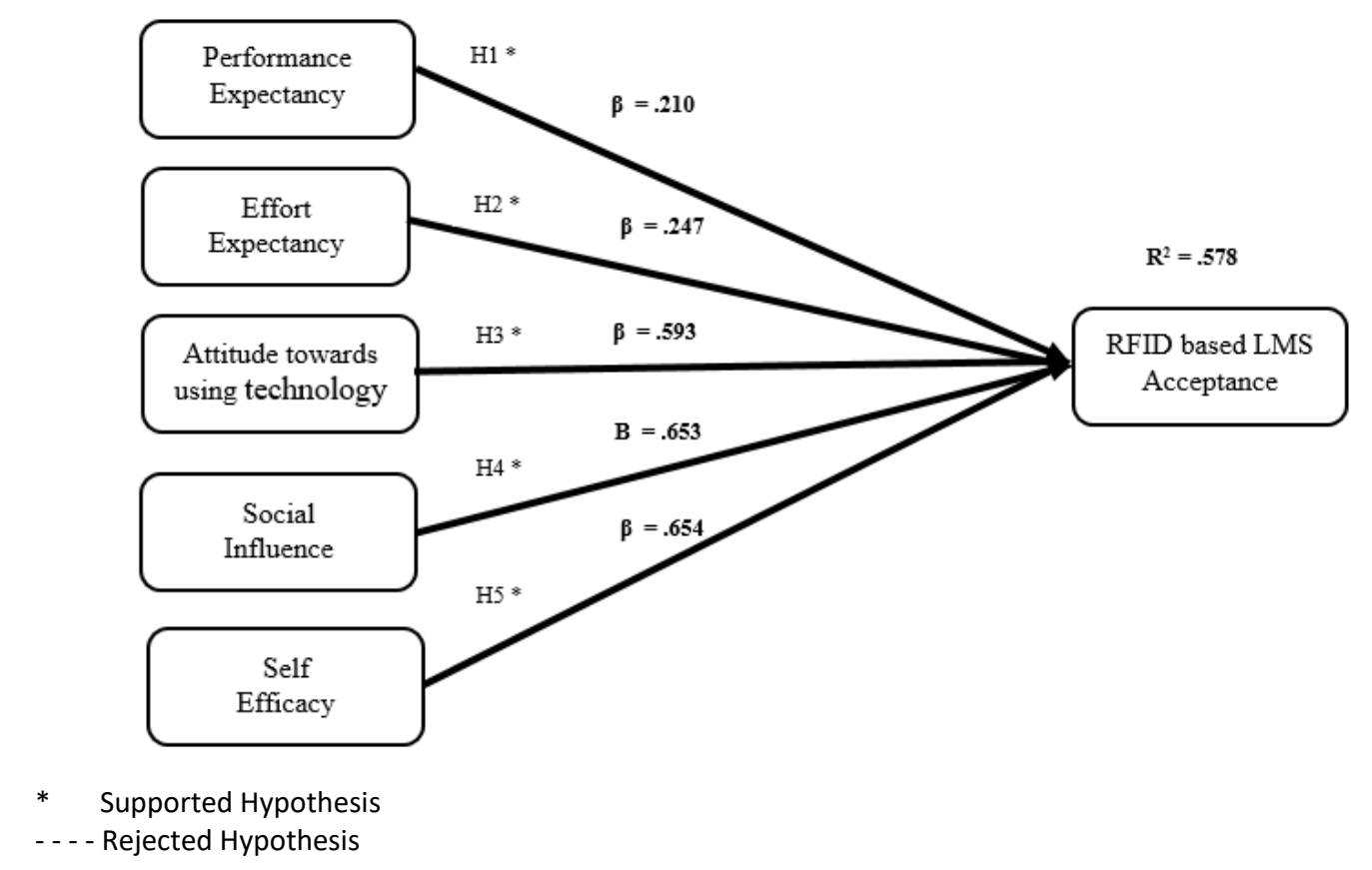

Figure 2: Factors' Influence on the Acceptance of RFID based LMS

\section{Hypothesis Testing}

The modified UTAUT model was tested for five research hypotheses (Figure 2) to examine if the independent variables collectively and significantly explained the variance in the dependent variable. Five of the hypotheses were supported $(\mathrm{H} 1, \mathrm{H} 2, \mathrm{H} 3, \mathrm{H} 4, \mathrm{H} 5)$. In general, the outcome shows that jointly the predictors explain $57.8 \%$ of the variability in behaviour intention to use RFID-LMS. Both PE and EE (original UTAUT), and newer external indicators, attitude and self-efficacy (Jong and Wang 2009; Yeow et al. 2008) are revealed to be appropriate constructs to explain RFID-LMS acceptance. Librarians' self-efficacy and attitude towards technology have a strong influence on RFID-LMS acceptance. Though several studies supported the social influence (SI) construct in use and acceptance of electronic library services or e-resources (Ayele and Sreenivasarao 2013; Awwad and AlMajali 2015; Chang et al. 2015), this study found it to be not significant in explaining RFIDLMS acceptance by Malaysian librarians. Most studies focus on the users of library services, the students, who show a tendency to be influenced by their social cycle when accepting to use electronic services of a library. In this study, the SI construct was introduced to measure the effect of members of the library management, the automation personnel and also other librarians had on the librarian's decision to accept the use RFID-LMS. The findings clearly indicate that this effect is also significant. Librarians are not influenced by their superiors or technical personnel. They are confident that if the system is easy to use, with least effort (EE), and contributes to completing their task (PE) and they have the ability to complete the task with little assistance (SE), then they would readily use the system. This is evident in the effect of self-efficacy (beta=0.654) on the acceptance variable. This study supports librarians' attitude as a determinant for RFID-LMS acceptance. As for self-efficacy, librarians' confidence in their ability to perform the tasks required by the RFID-LMS skilfully is a strong determinant in the acceptance of the RFIDLMS use. 


\section{Performance of the Validated Adapted Model}

This study also aimed to ascertain the performance of UTAUT with regards to its reliability and consistency across different contexts as compared to its original intent. The UTAUT model is empirically supported in this study. The reliability and consistency of the UTAUT model is found to be applicable, reliable, accurate and in uniformity with the original UTAUT (Venkatesh et. al 2013), and other studies on general acceptance and usage of technology (Anderson and Schwager 2004; Louho, Kallioja and Oittinen 2006; Kripanont 2007; Schaper and Pervan 2007; Ain, Kaur and Waheed 2015). These results have an important implication on the theoretical foundation of the unified theory and strongly supports the conjecture of a unified view of technology acceptance.

In general, the performance of the adapted UTAUT model in this study is comparative to the original UTAUT model. The $\mathrm{R}^{2}$ value illustrates $57.8 \%$ of the variance is explained by the five significant constructs, performance expectancy, effort expectancy, attitude, social influence and self-efficacy.

The adjusted $R^{2}$ (Figure 2$)$ falls within the average $R^{2}(0.30<R 2<0.700 .39)$ reported by Dwivedi et al. (2011) and the $R^{2}(0.39)$ of the original UTAUT. Though PE was the main indicator in the original UTAUT, in the context of librarians' acceptance of RFID based LMS, $P E$ is the least contributing indicator. Performance expectancy has a smaller effect $(\beta=.21)$ in the research model compared to the original model $(\beta=.34)$, but effort expectancy has a larger value $(\beta=.247)$ in the research model compared to the original model $(\beta=.14)$. Selfefficacy and attitude towards RFID-LMS are stronger predictors in this research model. This study results suggest the UTAUT model can consistently perform in context other than its original intent, with justified adaptations and inclusion of other external variables.

\section{CONCLUSION}

RFID based LMS is gaining popularity but the adoption in academic libraries is not as massive as expected, more so in Malaysia. This study attempted to investigate the antecedents of RFID based LMS acceptance by academic librarians. Findings reveal that performance expectancy, effort expectancy, attitude towards technology, social influence and self-efficacy have an effect on librarians' acceptance of RFID based LMS. This study will convince the librarians' acceptance on the demanding technology application system for the RFID based LMS. The technology is focused to the HF RFID and Web based Open Source LMS. This research model can be used and enhance the use of other RFID based applications in the library and other fields of information system and information science. This study is also applicable for other disciplines of study associated with different constructs focusing on the technology adoption and intention to use a system. Moreover, the study relates the results to the original UTAUT to ascertain if the performance of UTAUT is consistence across variant technologies and users.

First, the results and findings disseminates the significant influence of the construct performance expectancy, effort expectancy, attitude towards using technology, social influence and self-efficacy are supported in the typical accepted UTAUT model for the RFID based LMS acceptance in the library. Next, the performance expectancy, effort expectancy, attitude towards using technology, social influence and self-efficacy inadequately influence for the acceptance, adoption and intention to use RFID based LMS. This indicates that the performance expectancy, effort expectancy, attitude towards using technology, social 
influence and self-efficacy are the most important factors in influencing the acceptance, adoption and intention to use the technology of RFID based LMS in the library. More importantly these findings contribute to the performance consistency of UTAUT in different context. It provides empirical evidence that attitude, social influence and selfefficacy are appropriate constructs to examine library systems in more mature groups of users. The twofold implications for practice are based on results and findings and the effect of the factors for the entire UTAUT RFID based LMS acceptance. The findings of the UTAUT model is a practical solution. These solutions lead and guide the library practitioners to make an effort for the adoption and intention to use a RFID based LMS solution by focusing on performance expectancy, effort expectancy, attitude towards using technology, social influence and self-efficacy for service enhancement in the library. This study has several limitations, mainly in sampling and the technology investigated. The data is gathered from a single university library, involving librarians ranging from junior to senior staff members. The librarians experience (or inexperience) with RFID technology may have biased the results. Another limitation is the scope underlying technology of RFID which supports the library management system (LMS) operations and services. The high frequency (HF) RFID technology is implied in the technology acceptance with LMS. Therefore, future work on the use and user acceptance should focus on the ultra-high frequency (UHF) RFID technology with LMS. Future research can also extend the investigation by including moderating variables for RFID-LMS acceptance. Furthermore, by identifying relevant constructs to the context of the technology under study and ascertaining the diversity of UTAUT application, this study enhances the possible adoption of a unified theory of acceptance for successful innovation implementations in libraries.

\section{ACKNOWLEDGEMENT}

The study acknowledges the support received from University of Malaya grant PG1442015B.

\section{REFERENCES}

Ain, N., Kaur, K., and Waheed, M. 2015. The influence of learning value on learning management system use: An extension of UTAUT2. Information Development, Vol. 32, no. 5: 1306 - 1321. doi: 0266666915597546.

Andaleeb, S.S., and Simmonds, P.L. 1998. Explaining user satisfaction with academic libraries: strategic implications. College \& Research Libraries, Vol. 59, no. 2: 156-167.

Ajzen, I. 1991. The theory of planned behaviour. Organizational Behaviour and Human Decision Processess, Vol. 50: 179-211.

Al-Qeisi, K.I. 2009. Analyzing the use of UTAUT model in explaining an online behaviour: Internet banking adoption (Doctoral dissertation, Brunel University Brunel Business School PhD Theses). Available at: http://bura.brunei.ac.uk/bitstream/2438/kholoudThesis.pdf.

Anderson, J.E. and Schwager, P.H. 2004. SME adoption of wireless LAN technology: applying the UTAUT model. Proceedings of the $7^{\text {th }}$ Annual Conference of the Southern Association for Information Systems. Available at: http://sais.aosnet.org/sais2004/Anderson percent20\&percent20Schwagers.pdf.

Awwad, M. S., and AI-Majali, S.M. 2015. Electronic library services acceptance and use: an empirical validation of unified theory of acceptance and use of technology. The Electronic Library, Vol. 33, no. 6: 1100-1120. 
Ayele, A.A., and Sreenivasarao, V. 2013. A case study of acceptance and use of electronic library services in universities based on SO-UTAUT model. International Journal of Innovative Research in Computer and Communication Engineering, Vol. 1, no. 4: 903911.

Bingsi, F., and Xiaojing, H. 2006. Library 2.0: Building the New Library Services. Journal of Academic Libraries, Vol. 1: 2-5.

Carlsson, C., Carlsson, J., Hyvonen, K., Puhakainen, J., and Walden, P. 2006. Adoption of mobile devices/services-searching for answers with the UTAUT. In Proceedings of the 39th Annual Hawaii International Conference on System Sciences (HICSS'06) (Vol. 6, pp. 132a-132a). IEEE.

Chang, S. S., Lou, S. J., Cheng, S. R., and Lin, C. L. 2015. Exploration of usage behavioral model construction for university library electronic resources. The Electronic Library, Vol. 33, no. 2: 292-307.

Chang, C.C. 2013. Library mobile applications in university libraries. Library Hi Tech, Vol. 31, no.3: 478-492.

Dwivedi, Y.K., Rana, N.P., Chen, H. and Williams, M.D. 2011. A Meta-analysis of the Unified Theory of Acceptance and Use of Technology (UTAUT). In IFIP International Working Conference on Governance and Sustainability in Information Systems-Managing the Transfer and Diffusion of IT (pp. 155-170). Springer Berlin Heidelberg.

Dwivedi, Y.K., Kapoor, K., Williams, M.D., and Williams, J. 2013. RFID systems in libraries: An empirical examination of factors affecting system use and user satisfaction. International Journal of Information Management, Vol. 33, no. 2: 367377.

Gallego, M. D., Luna, P., and Bueno, S. 2008. User acceptance model of open source software. Computers in Human Behavior, Vol. 24, no. 5: 2199-2216.

Jasimudeen, S. 2013. Adoption and user perceptions of Koha library management system in India. Annals of Library and Information Studies (ALIS), Vol. 59, no. 4: 223-230.

Jong, D. and Wang, T.S., 2009. May. Student acceptance of web-based learning system. In Proceedings of the 2009 International Symposium on Web Information Systems and Applications (WISA'09), Vol. 8: 533-536.

Kripanont, N. 2007. Examining a technology acceptance model of internet usage by academics within Thai Business Schools (Doctoral dissertation, Victoria University).

Louho, R., Kallioja, M., and Oittinen, P. 2006. Factors affecting the use of hybrid media applications. Graphic arts in Finland, Vol.35, no. 3: 11-21.

Pervaiz, A. and Brogan, M. 2016. E-book user behaviour in academic libraries: The role of user agents in perception and satisfaction. Malaysian Journal of Library \& Information Science, Vol. 21, no. 3: 95-109.

Roscoe, J.T. 1975. Fundamental research statistics for the behavioral sciences. New York, NY: Holt, Rinehart and Winston.

Schaper. L.K. and Pervan, G.P. 2007. An investigation of factors affecting technology acceptance and use decisions by Australian allied health therapists. Available at ttp://csdl2.computer.org/comp/proceedings/hics/2007/2755/00/27550141.pdf.

Santos-Feliscuzo, L.T. and Himang, C.M. 2011. Library periodical indexing software evaluation using Unified Theory of Acceptance and Use of Technology. Procedia-Social and Behavioral Sciences, Vol. 25: 104-114.

Tibenderana, P.K. and Ogao, P.J. 2009. Information technologies acceptance and use among universities in Uganda: a model for hybrid library services end-users. International Journal of Computing and ICT Research, Vol. 1, no. 1:60-75. Available at: http://www.ijcir.org/special-issuevolumel-number1/article8.pdf. 
Venkatesh, V., Morris, M.G., Davis, F.D., and Davis, G.B. 2003. User acceptance of information technology: Toward a unified view. MIS Quarterly, Vol. 27:425-478. Available at: http://vvenkatesh.com/Downloads/Papers/fulltext/pdf/Venkatesh_Thong_Xu_MISQ_ forthcoming.pdf.

Vongjaturapat, S., Chaveesuk, S., Chotikakamthorn, N., and Tongkhambanchong, S. 2015. Analysis of factor influencing the tablet acceptance for library information services: A combination of UTAUT and TTF Model. Journal of Information \& Knowledge Management, Vol. 14, no. 3: 1550023.

Wasitarini, D. E., and Tritawirasta, W. 2015. Assessing users' acceptance toward a closed access Library Service System using the UTAUT model: A case study at the National Library of Indonesia. In 2015 International Conference on Information Technology Systems and Innovation (ICITSI) (pp. 1-4). IEEE.

Waheed, M., Kaur, K., Ain, N., and Sanni, S.A. 2015. Emotional attachment and multidimensional self-efficacy: extension of innovation diffusion theory in the context of eBook reader. Behaviour \& Information Technology, Vol. 34, no. 12: 1147-1159.

Wu, Y.L., Tao, Y.H., and Yang, P.C. 2007. Using UTAUT to explore the behavior of $3 \mathrm{G}$ mobile communication users. Paper presented at the 2007 IEEE International Conference on Industrial Engineering and Engineering Management. doi: 10.1109/IEEM.2007.4419179.

Yeow, P.H., Yuen, Y.Y., Tong, D.Y.K. and Lim, N., 2008. User acceptance of online banking service in Australia. Communications of the IBIMA, Vol. 1, no. 22:191-197.

Zhou,T., Lu,Y, and Wang, B. 2010. Integrating TTF and UTAUT to explain mobile banking adoption. Computers in Human Behavior, Vol. 26, no. 4:760-767.

Zhussupova, A., and Rahman, A.A. 2011. Open source software adoption in public organizations of Kazakhstan. Paper presented at the 2011 IEEE Conference on Open Systems (ICOS). doi: 10.1109/ICOS.2011.6079306. 